This is the author's final, peer-reviewed manuscript as accepted for publication. The publisher-formatted version may be available through the publisher's web site or your institution's library.

\title{
Optimal control of voltage and power in a multi zonal MVDC shipboard power system
}

Padmavathy Kankanala, Suresh C. Srivastava, Anurag K. Srivastava, Noel N. Schulz

How to cite this manuscript

If you make reference to this version of the manuscript, use the following information:

Kankanala, P., Srivastava, S. C., Srivastava, A. K., \& Schulz, N. N. (2012). Optimal control of voltage and power in a multi zonal MVDC shipboard power system. Retrieved from http://krex.keu.edu

\section{Published Version Information}

Citation: Kankanala, P., Srivastava, S. C., Srivastava, A. K., \& Schulz, N. N. (2012). Optimal control of voltage and power in a multi zonal MVDC shipboard power system. IEEE Transactions on Power Systems, 27(2), 642-650.

Copyright: (C) 2012 IEEE

Digital Object Identifier (DOI): doi:10.1109/TPWRS.2011.2178274

Publisher's Link: http://ieeexplore.ieee.org/xpl/articleDetails.jsp?arnumber=6135527

This item was retrieved from the K-State Research Exchange (K-REx), the institutional repository of Kansas State University. K-REx is available at http://krex.ksu.edu 


\title{
Optimal Control of Voltage and Power in a Multi Zonal MVDC Shipboard Power System
}

\author{
Padmavathy Kankanala, Student Member, IEEE, Suresh C Srivastava, Senior Member, IEEE, \\ Anurag K Srivastava, Senior Member, IEEE, Noel N Schulz, Senior Member, IEEE
}

\begin{abstract}
The Multi-Zonal Medium Voltage DC (MVDC) Shipboard Power System (SPS) architecture, proposed by the U.S Navy for their future combatant system, consists of several Voltage Source Converters (VSCs). The proposed architecture is tightly-coupled, power-limited and its performance needs to be evaluated for security, reliability, and survivability. Following system damage or a fault, the current flow pattern in the DC network may change, which may result in the failure of VSCs due to overvoltage developed across them in certain operating conditions. For a given MVDC system, DC voltage reference setting for one of the VSCs operating in the voltage regulator mode, and the optimal power reference settings of the remaining VSCs in the power dispatcher mode have to be pre-determined. These settings and control modes of VSCs are needed to maintain the DC voltage within desired margins (usually $5 \%$ around the nominal DC voltage), both in 'pre-fault' and 'post-fault outage' conditions. The problem has been formulated as an optimization problem with three different objective functions. Computational intelligence techniques have been applied for solving the optimization problem. These include the Genetic Algorithm (GA) and Biogeography Based Optimization (BBO) methods. The results have been compared with a conventional Lagrange Multiplier based method.
\end{abstract}

Keywords--MVDC power system, Voltage-source converter, Voltage sensitivity based method, Optimization, Genetic Algorithm (GA), Biogeography Based Optimization (BBO), shipboard power system.

\section{NOTATIONS}

$P_{i} \quad:$ Real power of the $\mathrm{i}^{\text {th }}$ converter $\left(\mathrm{VSC}_{\mathrm{i}}\right)$

$P_{\text {ref }} \quad$ : Real power reference of the VSC

$V_{\text {dcref }}:$ DC voltage reference of DC Voltage Regulator

$V_{d c i}:$ DC voltage of the $\mathrm{i}^{\text {th }}$ converter $\left(\mathrm{VSC}_{\mathrm{i}}\right)$

$V_{\min }:$ Minimum voltage limit

$V_{\max } \quad$ : Maximum voltage limit

$P_{\min } \quad$ : Minimum Power limit

$P_{\max } \quad$ : Maximum Power limit

\section{INTRODUCTION}

$\mathrm{W}$ ITH the U.S. Navy proposing a Medium Voltage DC (MVDC) distribution architecture for the all-electric ship Shipboard Power Systems (SPSs) [1,2], utilizing the recent developments in the power electronic converters, such

* Padmavathy Kankanala and Noel N Schulz are with Department of Electrical and Computer Engineering, Kansas State University, Manhattan, KS 66502, USA (e-mail: pk150@ksu.edu and noels@ksu.edu)

Suresh C Srivastava is with Department of Electrical Engineering, Indian Institute of Technology, Kanpur, 208016, India (e-mail: scs@iitk.ac.in)

Anurag K Srivastava is with School of Electrical Engineering and Computer Science, Washington State University, Pullman, WA 99164, USA (e-mail: asrivast@eecs.wsu.edu) as VSC (voltage source converters), calls for more research to maintain the reliability and survivability of the system [1]. The VSC based MVDC SPSs are tightly coupled, powerlimited systems. A multi-zonal MVDC SPS will employ several VSCs exchanging power through a DC network [2]. When a DC fault occurs in the electrical systems as a result of battle damage or equipment failure, the overall impact is a steady state change in the DC voltage across the VSCs [4]. This may lead to failure in the solid-state switches. Hence, the DC voltage should be maintained within a narrow range under pre-fault and post-fault outage conditions. The tightly couples nature of the SPS requires coordinated control to keep values within tight parameters and prevent additional faults or damage to equipment. While protection equipment will remove the fault, the VSCs are tasked with maintaining the voltage within a narrow range. In order for the VSCs to quickly manage the change in voltage, it is necessary to predeterminate the optimal power reference of the VSCs , for a given setting of the DC voltage reference of the VSC in voltage regulator mode. Because of this need, it is desirable to find an accurate numerical method that solves the optimization problem quickly and determines the reference settings. In this paper, only steady state faults are studied. The small signal and transient stability analysis was studied in [26].

$\mathrm{Lu}$ [5] developed an algorithm for optimal control of multiterminal HVDC (MTDC) based on voltage source converters. The operation of point-to-point VSC-HVDC requires one of the VSCs to operate in DC voltage regulator and the remaining in the power dispatcher mode $[6,7]$. As detailed in $[5,6,7]$, an MTDC system generally consists of several VSCs, connected in shunt to a DC network, in power dispatcher mode with one in DC voltage regulator mode. The feedback control of the DC voltage regulator is configured so that it regulates the DC voltage across its DC bus. Since the DC voltage across the DC bus depends on the charging of the DC capacitors, the $\mathrm{DC}$ voltage regulator controls the $\mathrm{AC}$ real power through it to null the error between the measured DC voltage and the $\mathrm{DC}$ voltage reference. The $\mathrm{DC}$ voltage regulator acts as a power slack because, while keeping the DC voltage charged to its reference setting, it maintains the power balance in the DC network. The DC voltage regulator takes on the complementary role (acting as inverter or rectifier) as a power slack to maintain power balance in the DC system.

The above process can be formulated as an optimization problem. Linear Programming and Gradient based techniques have been proposed in the literature for solving this problem $[12,15]$. However, due to the approximations introduced with the linearized models, these conventional methods may not give the optimal solution for inherently non-linear, non- 
differentiable objective functions. Also, these conventional methods are known to converge to a local optimal rather than the global solution. This paper reports two of the evolutionary computation techniques, Genetic Algorithm (GA) and Biogeography Based Optimization (BBO) methods. Although the genetic algorithm method has been used for different power system optimization applications, none of these have been applied for MVDC system. This paper is concerned with the application of these two techniques for optimal control of the DC voltage and power in the multi-zonal MVDC system. Conventional and the intelligent techniques to solve this optimization problem, while satisfying the power balance requirement, voltage constraints and the power constraints are developed and have been tested on a simplified model of the Multi-zonal MVDC SPS.

Genetic algorithms (GAs) have been used to solve problems with objective functions that do not possess properties such as continuity and differentiability. This algorithm maintains and manipulates a family, or population, of solutions and implements a survival of the fittest strategy in the search for better solutions [21]. GAs search the solution of a function through the use of simulated evolution, i.e., the survival of the fittest strategy. In general, the fittest individuals of any population tend to reproduce and survive to the next generation, thus improving successive generations. However, inferior individuals can, by chance, survive and also reproduce. GAs have been shown to solve linear and nonlinear problems by exploring all regions of the state space and exponentially exploiting promising areas through mutation, crossover, and selection operations applied to the individuals in the population.

Biogeography Based optimization (BBO) is a populationbased evolutionary algorithm (EA) that is based on the mathematics of biogeography [19]. Biogeography is the study of the geographical distribution of biological organisms. This paper presents a simplified version of the $\mathrm{BBO}$ and then analysis of its population using probability theory is carried out. The analysis provides approximate values of the expected number of generations before the population's best solution improves, and the expected amount of improvement. These expected values are functions of the population size. Three behaviors are quantified as the population size increases: first, the best solution in the initial randomly-generated population improves; second, the expected number of generations before improvement increases; and the third, the expected amount of improvement decreases. The application of the biogeography to the optimization was first presented in [23] and is an example of how a natural process can be modeled to solve general optimization problems. As optimization techniques, GAs and BBOs are much less dependent on the initial values of the variables in the optimization problem unlike the widely used conventional methods. The advantages of GA and BBO method over the other optimization methods are in [25].

The remaining sections of this paper have been organized as follows. Section II briefly describes a multi-zonal MVDC shipboard power system architecture. Section III discusses the mathematical formulation of the three different alternative objective functions and section IV describes the conventional and the intelligence techniques based algorithms to solve the optimization problems. Section $\mathrm{V}$ presents the test results obtained on the multi-zonal MVDC shipboard power system. Finally, the paper concludes in Section VI.

\section{MULTI-ZONAL MVDC SHIPBOARD POWER SYSTEM ARCHITECTURE}

In MVDC architecture, the main power distribution can utilize DC supply at standard voltages ranging between \pm $3000 \mathrm{~V}$ DC to $\pm 10,000 \mathrm{~V}$ DC using a high-impedance ground. A notional shipboard MVDC power system architecture, as proposed in [3], is shown in figure 1. This MVDC architecture utilizes a medium voltage DC ring bus, operating at $5 \mathrm{kV}$, fed from the two main and the two auxiliary generators (MTG1, MTG2, ATG1, and ATG2) through transformers and rectifiers. The DC power is distributed along the length of the ship in five zones. The loads, converters, Power Conversion Modules (PCMs) and Power Distribution Modules (PDMs), are distributed in these zones.

Loads, requiring $800 \mathrm{~V} \mathrm{DC}$, are supplied with the help of PCM1, which converts $5000 \mathrm{~V}$ DC power to $800 \mathrm{~V}$ DC. PCM4s are typically connected to the generators for $\mathrm{AC}$ to $\mathrm{DC}$ conversion. Other zonal loads, which require $\mathrm{AC}$ (such as propulsion motor load), are fed with the help of PCM2, which converts DC- AC. It also has converter-driven energy storage devices, such as a bank of capacitors or fuel cells, a pulsed load device, such as the charging circuit for a free electron laser gun, and high power sensors, such as a radar array. This study has considered a simplified model of the Multi-Zonal MVDC shipboard power system architecture. All the loads are considered as lumped loads on the DC busbar.

\section{MATHEMATICAL FORMULATION}

In a multi-terminal MVDC distribution system, a VSC converter can be operated either in the DC voltage regulator mode or in power dispatcher mode. In this work, one of the VSCs is assumed to operated in DC voltage regulator mode, say $(\mathrm{N}+1)^{\text {th }}$ converter in a MVDC system having total $(\mathrm{N}+1)$ VSCs, and the remaining ones in the power dispatcher mode. The reference setting of the VSC in voltage regulator mode can be taken to the nominal or near nominal DC voltage rating, but it is required to determine the optimal reference power setting of the remaining $\mathrm{N}$ converters in the power dispatcher mode, ensuring that the DC voltage across these VSCs also remains within acceptable limits in the pre-fault system condition as well as under failure of one of the VSCs in the power dispatcher mode. The outage of the VSC in the voltage regulator mode is not considered for the sake of simplicity, but in case it is simulated, one of the remaining VSC has to be considered to operate under the voltage regulator mode. These settings can be maintained by the inbuilt control scheme of each VSC, which is not modeled in this work, as the main focus of the paper is the steady state, coordinated optimal operation of VSCs. This problem has been formulated as an optimization problem to determine the optimal references power setting of the VSCs in the power dispatcher mode. Optimization problem satisfies the system operating constraints not only under the base case pre-fault system condition, but also under outage of the VSCs, taken one at a time in the power dispatcher mode. 


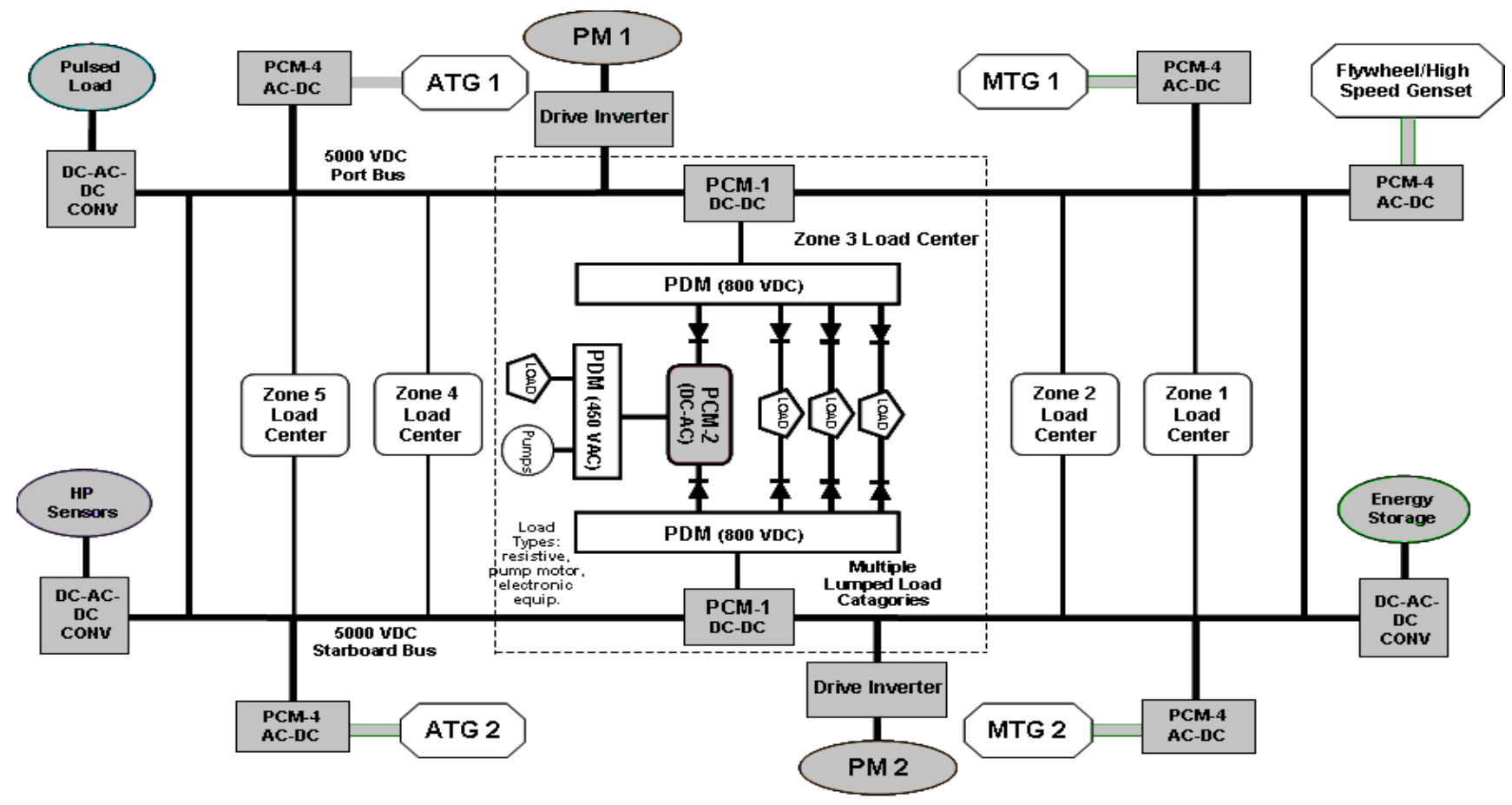

Figure 1. Proposed MVDC architecture for shipboard power system [3]

The solution has been obtained by a classical Lagrange Multiplier approach [8], and two evolutionary algorithms, satisfying the voltage and power constraints. An existing formulation of the problem and two new alternate formulations have been utilized as described below.

\section{A. Problem formulation:}

The objective is to find the power settings $P_{1}^{s p}, P_{2}^{s p}, \ldots \ldots \ldots . ., P_{N}^{s p}$ which allow $V_{\text {min }} \leq V_{i}^{k} \leq V_{\text {max }}$ i $=1,2, \ldots \mathrm{N}$ to be satisfied not only for the pre-fault case $(\mathrm{k}=0)$ but for every case of any one of the VSCs being lost ( $\mathrm{k}=\mathrm{i}$ indicates loss of the $\mathrm{i}^{\text {th }}$ VSC). For the case of $\mathrm{VSC}_{\mathrm{k}}$ being lost, $P_{k}^{\text {sp }}=0$, so that

$$
P^{k}=\left[P_{1}^{s p}, P_{2}^{s p}, \ldots \ldots, P_{k-1}^{s p}, 0, P_{k+1}^{s p}, \ldots \ldots, P_{N}^{s p}\right]^{\top}
$$

\section{B. Power Limits}

The VSCs have power limits because of their MVA ratings or because of contractual commitments to supply sensitive loads. The power limits are denoted as $P_{\min }=\left[P_{\min l}, P_{\min 2}, \ldots \ldots . P_{\operatorname{minN}}\right]^{\mathrm{T}}{ }^{\mathrm{and}} P_{\max }=\left[P_{\mathrm{max}}, P_{\mathrm{max}} \ldots \ldots . P_{\max }\right]^{T}$.

The minimization of a function, which will ensure that the power limits are observed, can be $\sum\left(P^{k}-P_{\min }\right)^{T}\left[W_{p}\right]\left(P^{k}-P_{\text {max }}\right)$.

The $\sum$ summation is taken over $\mathrm{k}=0,1,2 \ldots \mathrm{N}$. $\left[\mathbf{W}_{\mathbf{p}}\right]$ and is a $\mathrm{NxN}$ diagonal matrix of penalty weights.

\section{Voltage Limits:}

The DC voltage limits are denoted as $V_{\text {min }}=\left[V_{\min 1}, V_{\min 2}, \ldots \ldots, V_{\min N}\right]^{\mathrm{T}}$ and $\left.V_{\max }=\left[V_{\max }, V_{\max }, \ldots \ldots V_{\max }\right]^{\mathrm{T}}\right]^{\mathrm{m}}$. The minimization of a function, $\sum\left(V^{k}-V_{\min }\right)^{x}\left[W_{v}\left(V^{k}-V_{\max }\right)\right.$, ensures the compliance of voltages within the limits. $\left[\mathbf{W}_{\mathbf{v}}\right]$ is a
NxN diagonal matrix of penalty weights. However, the parameters for optimization are not $\mathbf{V}^{\mathrm{k}}$ but $P_{1}^{s p}, P_{2}^{s p}, \ldots \ldots \ldots, P_{N}^{s p}$. In fact, $\quad \mathbf{V}^{\mathrm{k}}$ is the solution of the equation $\left.P^{k}-\left|V^{k}\right| Y\right] V^{k}=0$ for the $\mathrm{N}+1$ bus MVDC system for cases pertaining to $\mathrm{k}=0,1,2 \ldots . \mathrm{N}$.

D. Formulation with the Power and Voltage Constraints:

By combining both the power limits and voltage limits, three different optimization formulations have been considered, as described below:

1. Existing Formulation [5]:

This considers the objective function to be minimized as

$$
\begin{aligned}
& C\left(P_{1}^{s p}, P_{2}^{s p}, \ldots \ldots, P_{N}^{s p}\right) \\
& =\left\{\begin{array}{c}
\left(P-P_{\text {min }}\right)^{T}\left[W_{p N}\right]\left(P-P_{\text {min }}\right) \\
+\left(P-P_{\text {max }}\right)^{T}\left[W_{p x}\right]\left(P-P_{\text {max }}\right)
\end{array}\right\} \\
& +\sum_{k=0}^{N}\left\{\begin{array}{c}
\left(V^{k}-V_{\min }\right)^{T}\left[W_{v N}\right]\left(V^{k}-V_{\text {min }}\right) \\
+\left(V^{k}-V_{\text {max }}\right)^{T}\left[W_{v x}\right]\left(V^{k}-V_{\text {max }}\right)
\end{array}\right\}
\end{aligned}
$$

subject to equality constraints,

$$
\left.P^{k}-\left\lfloor V^{k}\right\rfloor Y\right] V^{k}=0 \quad \mathrm{k}=0,1,2, \ldots \mathrm{N}
$$

In addition to the above, two new alternate formulations have been suggested with the objective functions as given below.

\section{Alternative-1 Formulation:}

This formulation tries to minimize the deviation of power from its target value $\left(P_{\text {tar }}\right)$ and deviation of DC voltage from its target value $\left(V_{t a r}\right)$. The target value of the power can be the 
base case desired values used as reference settings of the dispatchers and the target value of the DC bus voltages can be taken as the nominal value (1.0 p.u.).

$$
\begin{aligned}
& C\left(P_{1}^{s p}, P_{2}^{s p}, \ldots \ldots, P_{N}^{s p}\right) \\
= & \left\{\left(P-P_{\text {tar }}\right)^{T}\left[W_{p}\right]\left(P-P_{\text {tar }}\right)\right\} \\
+ & \sum_{k=0}^{N}\left\{\left(V^{k}-V_{\text {tar }}\right)^{T}\left[W_{V}\right]\left(V^{k}-V_{\text {tar }}\right)\right\}
\end{aligned}
$$

\section{Alternative-2 Formulation:}

This formulation minimizes the deviation of power from its maximum and minimum limiting values but the deviation of the DC voltage from its target value.

$$
\begin{aligned}
& C\left(P_{1}^{s p}, P_{2}^{s p}, \ldots \ldots, P_{N}^{s p}\right) \\
& =\left\{\begin{array}{c}
\left(P-P_{\min }\right)^{T}\left[W_{p N}\right]\left(P-P_{\text {min }}\right) \\
+\left(P-P_{\max }\right)^{T}\left[W_{p x}\right]\left(P-P_{\text {max }}\right)
\end{array}\right\} \\
& +\sum_{k=0}^{N}\left\{\left(V^{k}-V_{\text {tar }}\right)^{T}\left[W_{v}\right]\left[V^{k}-V_{\text {tar }}\right)\right\}
\end{aligned}
$$

In this work, all the weighing factors have been considered to be unity for the sake of testing the proposed algorithms.

\section{CONVENTIONAL AND INTELLIGENT TECHNIQUES ALGORITHMS}

The above three alternative formulations with different objective functions, along with the equality constraints, have been solved using three different techniques (i) Lagrange multiplier approach, based on first order gradient approach, (ii) Genetic Algorithm (GA) method and (iii) Biogeography Based Optimization (BBO) method.

\section{A. Lagrange Multiplier Method}

The main steps with this approach are as following:

1. Start with an initial value $(\mathrm{j}=0)$ of reference power settings $P(j)=\left[P_{1}^{s p}, P_{2}^{s p}, \ldots \ldots \ldots . . ., P_{N}^{s p}\right], \quad j$ being the iteration number.

2. Solve for $V^{k}=\left[V_{1}^{k}, V_{2}^{k}, \ldots \ldots, V_{N}^{k}\right]^{\text {from the power flow }}$ equations: $P^{k}-\left[V^{k} \mid Y\right] V^{k}=0$, for given value of the $(\mathrm{N}+1)$ th bus voltage.

3. Examine if the voltage or converter power limits are violated. Include the corresponding penalty terms in the objective function.

4. Compute mpte (the gradient of the objective $C\left(P_{1}^{s p}, P_{2}^{s p}, \ldots \ldots \ldots . . ., P_{N}^{s p}\right)$ with respect to $P_{1}^{s p}, P_{2}^{s p}, \ldots \ldots \ldots . ., P_{N}^{s p}$.

5. Update converter power, $P(j+1)=P(j)-\alpha \nabla P^{(j)}$, where $\alpha$ is a factor for modifying the step size. The $\alpha$ value is chosen by trial and error.

6. Repeat steps $2,3,4$, and 5 until $\left|\nabla P^{(j)}\right|$ is less than a prespecified tolerance.

\section{B. Genetic Algorithm method}

GAs are search techniques based on an analogy with the biology [20] in which a group of solutions evolved through natural selection. In their implementation, a population of randomly generated candidate solutions evolves to an optimum solution through the operation of genetic operators consisting of reproduction, crossover and mutation. Additional details on the GA for this application are available in [25].

The major computational steps are as follows:

1. Randomly generate a set of initial population within the search space.

2. Calculate the fitness for each chromosome in the population.

3. The algorithm creates a new population in each iteration. At each step, to create the new population, the algorithm performs the following steps:

a. Compute the fitness values for each chromosome.

b. Based on fitness value of each individual, select population.

c. The individuals (chromosomes) with the minimal fitness values are chosen from the current population and are passed to the next generation.

d. Through crossover and mutation process, generate the new population.

e. Replace the current population with the new population to form the next generation.

f. Check for feasibility of the solution, i.e. each chromosome should satisfy both the equality and inequality constraints.

4. Go to step 3 .

5. Terminate, if the stopping criteria has been reached, and return the solution.

\section{Biogeography Based Optimization}

Biogeography based Optimization (BBO) is founded [17] on the observation that the migration of species among a group of neighboring islands, combined with mutation of the individual species, will tend over many generations to produce islands that attract and keep large numbers of species through immigration. Other islands will lose species through extinction or emigration and will sometimes become desolate. The BBO algorithm seeks to model this behavior in a way that causes an "optimal" island to emerge from the original population of islands.

In a group of neighboring islands, species of plants and animals will migrate over time between the islands by various means, being carried along by driftwood, fish, birds, and the wind. Over evolutionary periods of time, some islands may tend to accumulate more species than others because they posses certain environmental features that are more suitable to sustaining those species than islands with fewer species. This ability to sustain larger numbers of species can be associated with a fitness measure that we can quantify by assigning an Habitat suitability index (HSI) to each island. The value of the HSI depends on many features of the island. If a value is assigned to each feature, then the HSI is a function of these values. Each of these values is represented by a suitability index variable (SIV). These mappings are summarized as follows:

Island $\rightarrow\left(\right.$ features $_{1}, \ldots \ldots$, featues $\left._{n}\right) \rightarrow\left(\mathrm{SIV}_{1}, \ldots, \mathrm{SIV}_{\mathrm{n}}\right) \rightarrow \mathrm{HIS}$ 
An island with a large number of species (a large HSI) has abundance of species which can emigrate to other islands, so its rate of emigration, denoted by $\mu$, is correspondingly large. The island is also less likely to be able to sustain further immigration of species because of the growing demand on its finite environmental resources, so its immigration rate, denoted by $\lambda$, is small. For many applications, it suffices to assume a linear relationship between an island's HSI and its immigration and emigration rates are the same for all islands under consideration (the population). These relationships are depicted in Figure 2.

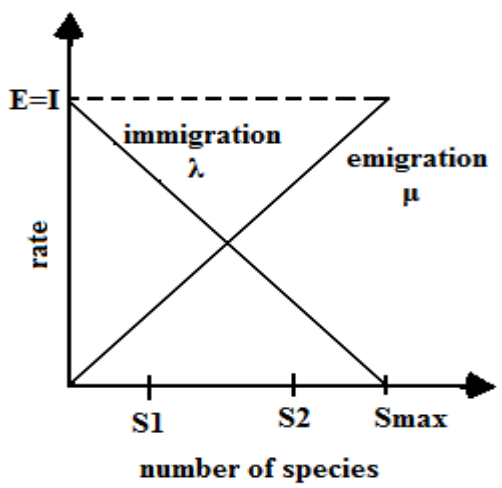

Figure 2. A Candidate Solution [17]

In order to apply the $\mathrm{BBO}$ concept to an optimization problem, the n-tuple $\left(\mathrm{SIV}_{1}, \ldots \ldots, \mathrm{SIV}_{\mathrm{n}}\right)$ associated with the features of an island is viewed as a possible solution to the optimization problem. In other words, the set of all such ntuples is the search space from which an optimal solution will be determined. The value of the HSI for a particular island is viewed as the value of the objective function associated with that solution. The goal of the BBO algorithm then is to determine the solutions which maximize the HSI over the entire search space.

One can use the migration rates of each solution to probabilistically share features between islands. For each SIV (feature) in each island (solution), one can probabilistically decide whether or not to immigrate. If immigration is selected for a given SIV, then the emigrating island is selected probabilistically. After the migration operation, a mutation operation is probabilistically applied to the island to increase diversity in the population. The major computation steps as shown in Figure 3 are as follows:

1. Initialize the BBO parameters.

2. The initial position of SIV of each habitat should be randomly selected, while satisfying different equality and inequality constraints of optimization problem. A group of habitats, depending upon the population size, are being generated. Each habitat represents a solution to the given problem.

3. Calculate the HSI, i.e. value of objective function for each habitat of the population set for given emigration rate $\mu$, immigration rate $\lambda$ and species $\mathrm{S}$.

4. In the Optimization problem $\mathrm{HSI}^{\mathrm{i}}$ indicates the objective function due to $i$-th set of generation value (i.e. $i$-th habitat).

5. Based on the HSI value, the elite habitants are identified.
6. Modify each non-elite habitat using immigration and emigration rates.

7. Update each habitant using $\lambda$ and recalculate each HSI.

8. Feasibility of a problem solution is verified, i.e. each SIV should satisfy equality and inequality constraints.

9. Go to step-3 for the next iteration.

10. Terminate if stopping condition has been reached.

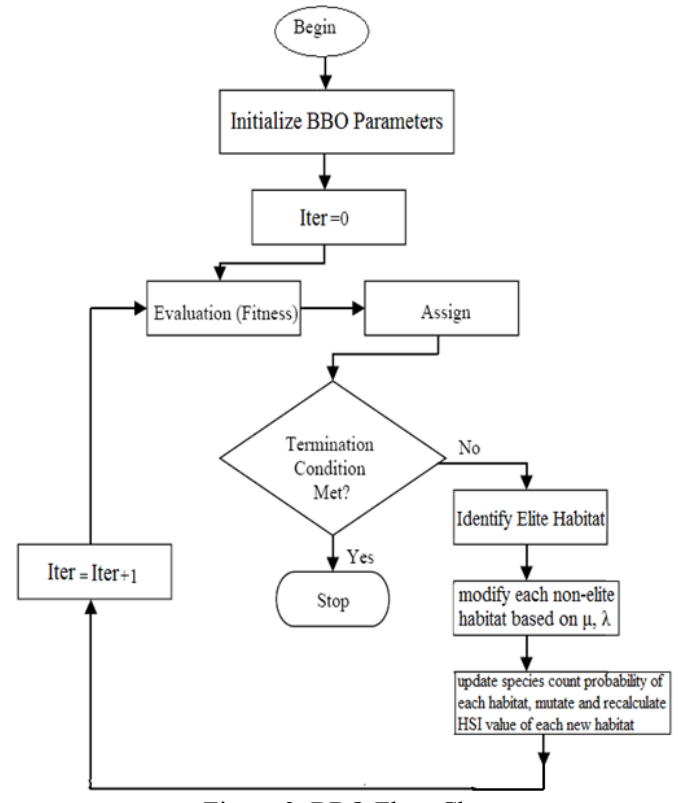

Figure 3. BBO Flow Chart

\section{SIMULATION RESULTS}

The proposed method of optimal voltage and power control has been tested on the simplified MVDC notional shipboard system, derived from Figure 4. Figure 4 shows a 7-bus simplified model of MVDC shipboard power system. In 7-bus MVDC SPS system shown in Figure 4, VSC7 is assigned to be DC Voltage Regulator and bus 5 is, therefore, the slack bus. VSC1 and VSC5 are assumed to act as rectifiers, connected to the main generators on the AC side.

TABLE I

POWER REFERENCE SETTINGS
\begin{tabular}{|l|l|}
\hline Bus \# & $\boldsymbol{F}^{\boldsymbol{m}}$ \\
\hline 1 & 0.01 \\
\hline 2 & 0.02 \\
\hline 3 & 0.25 \\
\hline 4 & 0.20 \\
\hline 5 & 0.15 \\
\hline 6 & 0.11 \\
\hline 7 & Slack bus \\
\hline
\end{tabular}

VSC2 and VSC3 are assumed to act as rectifiers, connected to the auxiliary generators on the $\mathrm{AC}$ side. All the loads are assumed to be fed from VSC4, operating as an inverter. The converter power settings are shown in Table I. The 5-bus simplified models of the multi-zonal MVDC SPS have been considered and these algorithms have been tested and comparison of the results has been done. More details can be found in [25]. As outlined in reference [3], all the DC line resistances are assumed to be 0.01 p.u. except for the line 
between bus $1 \&$ bus2 and bus7 \& bus3, whose resistance is taken as 0.1 p.u. The voltage limits are 0.95 p.u. $\leq \mathbf{V}_{\mathrm{i}} \leq 1.05$ p.u. at all the buses. The results of the two stages for determining the reference settings of the voltage regulators and power dispatchers are given below. Table II presents the results with the voltage sensitivity method [24]. As can be seen from this table, there is no feasible common range for $\mathrm{V}_{\text {ref }}$ of the voltage regulator.

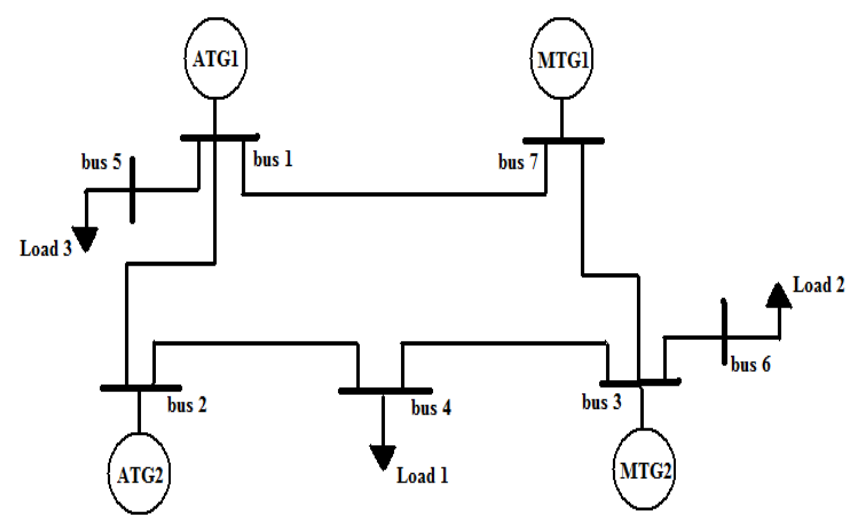

Figure 4. Simplified model of MVDC SPS

TABLE II.

ALLOWED $V_{\text {REF }}$ FOR DIFFERENT CASES

\begin{tabular}{|c|l|c|c|}
\hline \multirow{2}{*}{ No. } & Conditions & \multicolumn{2}{|c|}{$\begin{array}{l}\text { Allowable Voltage Reference } \\
\text { (p.u) }\end{array}$} \\
\cline { 3 - 4 } & & $\mathbf{V}_{\text {dcrefmin }}$ & $\mathbf{V}_{\text {dcrefmax }}$ \\
\hline 1 & All VSCs in service & 0.9704 & 1.0056 \\
\hline 2 & Loss of VSC1 & 0.9567 & $\mathbf{0 . 9 6 5 8}$ \\
\hline 3 & Loss of VSC2 & $\mathbf{0 . 9 9 5 2}$ & 1.0801 \\
\hline 4 & Loss of VSC3 & 0.9801 & 1.0234 \\
\hline 5 & Loss of VSC4 & 0.9362 & 0.9856 \\
\hline 6 & Loss of VSC5 & 0.9592 & 1.0922 \\
\hline 7 & Loss of VSC6 & 0.964 & 0.9974 \\
\hline $\begin{array}{l}\text { Accepted Common range for all } \\
\text { conditions }\end{array}$ & No Feasible Range Available \\
\hline
\end{tabular}

TABLE III

DC VOLTAGES SUBJECT TO VSC POWER SETTING ADJUSTMENT WITH ALTERNATIVE-1 FORMULATION

\begin{tabular}{|c|c|c|c|c|c|c|c|}
\hline \multirow[t]{2}{*}{ Conditions } & \multicolumn{7}{|c|}{ DC Voltage (p.u.) } \\
\hline & $\mathbf{V}_{\mathrm{dc} 1}$ & $\mathbf{V}_{\mathrm{dc} 2}$ & $\mathbf{V}_{\mathrm{dc} 3}$ & $\mathbf{V}_{\mathrm{dc} 4}$ & $\mathbf{V}_{\mathrm{dc} 5}$ & $\mathbf{V}_{\mathrm{dc} 6}$ & $\mathbf{V}_{\mathrm{dc} 7}$ \\
\hline $\begin{array}{l}\text { All VSCs } \\
\text { in service }\end{array}$ & 1 & 0.987 & 0.9954 & 0.9639 & 0.962 & 0.959 & 1 \\
\hline $\begin{array}{l}\text { Loss of } \\
\text { VSC1 }\end{array}$ & 0.992 & 0.984 & 0.993 & 0.96 & 0.982 & 0.964 & 1 \\
\hline $\begin{array}{l}\text { Loss of } \\
\text { VSC2 }\end{array}$ & 0.994 & 0.973 & 0.989 & 0.954 & 0.956 & 0.973 & 1 \\
\hline $\begin{array}{l}\text { Loss of } \\
\text { VSC3 }\end{array}$ & 0.993 & 0.971 & 0.964 & 0.989 & 0.974 & 0.974 & 1 \\
\hline $\begin{array}{l}\text { Loss of } \\
\text { VSC4 }\end{array}$ & 1.022 & 1.037 & 1.034 & 1.038 & 1.03 & 1.028 & 1 \\
\hline $\begin{array}{l}\text { Loss of } \\
\text { VSC5 }\end{array}$ & 0.987 & 0.978 & 0.959 & 0.974 & 0.971 & 0.979 & 1 \\
\hline $\begin{array}{l}\text { Loss of } \\
\text { VSC6 }\end{array}$ & 0.967 & 0.979 & 0.998 & 0.981 & 0.987 & 0.965 & 1 \\
\hline $\begin{array}{r}\text { Adjusted Cc } \\
\mathbf{P}_{\text {refl }}=0.00 \\
\mathbf{P}_{7}=0.235\end{array}$ & verter I & wer(p.u) & & & & & \\
\hline
\end{tabular}

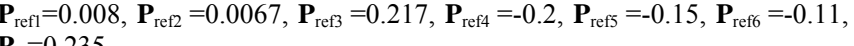
$\mathbf{P}_{7}=0.235$
TABLE IV

DC VOLTAGES SUBJECT TO VSC POWER SETTING ADJUSTMENT WITH EXISTING FORMULATION [5]

\begin{tabular}{|l|l|l|l|l|l|l|r|}
\hline \multirow{2}{*}{ Conditions } & \multicolumn{7}{|c|}{ DC Voltage (p.u.) } \\
\cline { 2 - 9 } & $\mathbf{V}_{\text {dc1 }}$ & $\mathbf{V}_{\text {dc2 }}$ & $\mathbf{V}_{\text {dc3 }}$ & $\mathbf{V}_{\text {dc4 }}$ & $\mathbf{V}_{\text {dc5 }}$ & $\mathbf{V}_{\text {dc6 }}$ & $\mathbf{V}_{\text {dc7 }}$ \\
\hline $\begin{array}{l}\text { All VSCs } \\
\text { in service }\end{array}$ & 0.983 & 0.96 & 0.979 & 0.9546 & 0.9591 & 0.956 & 1 \\
\hline $\begin{array}{l}\text { Loss of } \\
\text { VSC1 }\end{array}$ & 0.982 & 0.966 & 0.971 & 0.9643 & 0.965 & 0.984 & 1 \\
\hline $\begin{array}{l}\text { Loss of } \\
\text { VSC2 }\end{array}$ & 0.982 & 0.959 & 0.978 & 0.9632 & 0.981 & 0.973 & 1 \\
\hline $\begin{array}{l}\text { Loss of } \\
\text { VSC3 }\end{array}$ & 0.979 & 0.953 & 0.957 & 0.9576 & 0.9562 & 0.9901 & 1 \\
\hline $\begin{array}{l}\text { Loss of } \\
\text { VSC4 }\end{array}$ & 1.005 & 1.009 & 1.015 & 1.0188 & 0.987 & 1.0012 & 1 \\
\hline $\begin{array}{l}\text { Loss of } \\
\text { VSC5 }\end{array}$ & 1.031 & 1.019 & 0.998 & 1.0278 & 1.01 & 0.9985 & 1 \\
\hline $\begin{array}{l}\text { Loss of } \\
\text { VSC6 }\end{array}$ & 0.986 & 0.976 & 0.963 & 0.9744 & 0.9545 & 0.96731 & 1 \\
\hline $\begin{array}{l}\text { Adjusted Converter Power(p.u) } \\
\mathbf{P}_{\text {ref1 }}=0.0041, \mathbf{P}_{\text {ref2 }}=0.0088, \mathbf{P}_{\text {ref3 }}=0.187, \mathbf{P}_{\text {ref4 }}=-0.2, \mathbf{P}_{\text {ref5 }}=-0.15, \mathbf{P}_{\text {ref6 }}=-0.11, \\
\mathbf{P}_{7}=0.2601\end{array}$ \\
\hline
\end{tabular}

TABLE V

DC VOLTAGES SUBJECT TO VSC POWER SETTING ADJUSTMENT FOR ALTERNATIVE-2 FORMULATION

\begin{tabular}{|l|l|l|l|l|l|l|r|}
\hline \multirow{2}{*}{ Conditions } & \multicolumn{7}{|c|}{ DC Voltage (p.u.) } \\
\cline { 2 - 9 } & $\mathbf{V}_{\mathrm{dc} 1}$ & $\mathbf{V}_{\mathrm{dc} 2}$ & $\mathbf{V}_{\mathrm{dc} 3}$ & $\mathbf{V}_{\mathrm{dc} 4}$ & $\mathbf{V}_{\mathrm{dc} 5}$ & $\mathbf{V}_{\mathrm{dc} 6}$ & $\mathbf{V}_{\mathrm{dc} 7}$ \\
\hline $\begin{array}{l}\text { All VSCs } \\
\text { in service }\end{array}$ & 0.9826 & 0.9600 & 0.979 & 0.956 & 0.9982 & 0.953 & 1 \\
\hline $\begin{array}{l}\text { Loss of } \\
\text { VSC1 }\end{array}$ & 0.982 & 0.9595 & 0.972 & 0.964 & 0.9847 & 0.986 & 1 \\
\hline $\begin{array}{l}\text { Loss of } \\
\text { VSC2 }\end{array}$ & 0.982 & 0.9586 & 0.978 & 0.963 & 0.95748 & 0.974 & 1 \\
\hline $\begin{array}{l}\text { Loss of } \\
\text { VSC3 }\end{array}$ & 0.979 & 0.9532 & 0.957 & 0.957 & 0.9652 & 0.964 & 1 \\
\hline $\begin{array}{l}\text { Loss of } \\
\text { VSC4 }\end{array}$ & 1.004 & 1.0095 & 1.015 & 1.018 & 0.9819 & 1.001 & 1 \\
\hline $\begin{array}{l}\text { Loss of } \\
\text { VSC5 }\end{array}$ & 0.992 & 0.9678 & 0.963 & 0.974 & 0.9743 & 0.975 & 1 \\
\hline $\begin{array}{l}\text { Loss of } \\
\text { VSC6 }\end{array}$ & 0.983 & 0.9703 & 0.597 & 0.967 & 0.9987 & 0.969 & 1 \\
\hline $\begin{array}{l}\text { Adjusted Converter Power(p.u) } \\
\mathbf{P}_{\text {ref1 }}=0.0044, \mathbf{P}_{\text {ref2 }}=0.0091, \mathbf{P}_{\text {ref3 }}=0.267, \mathbf{P}_{\text {ref4 }}=-0.2, \mathbf{P}_{\text {ref5 }}=-0.15, \mathbf{P}_{\text {ref6 }}=-\end{array}$ \\
$0.11, \mathbf{P}_{7}=0.1795$
\end{tabular}

TABLE VI

DC VOLTAGES SUBJECT TO GA BASED VSC POWER SETTING ADJUSTMENT WITH ALTERNATIVE-1 FORMULATION

\begin{tabular}{|l|l|l|l|l|l|l|r|}
\hline \multirow{2}{*}{$\begin{array}{l}\text { Condition } \\
\mathrm{s}\end{array}$} & \multicolumn{7}{|c|}{ DC Voltage (p.u.) } \\
\cline { 2 - 9 } $\begin{array}{l}\text { All VSCs } \\
\text { in service }\end{array}$ & 0.981 & 0.975 & 0.956 & 0.961 & 0.962 & 0.962 & 1 \\
\hline $\begin{array}{l}\text { Loss of } \\
\text { VSC1 }\end{array}$ & 0.985 & 1.003 & 0.985 & 0.956 & 0.965 & 0.969 & 1 \\
\hline $\begin{array}{l}\text { Loss of } \\
\text { VSC2 }\end{array}$ & 0.965 & 0.976 & 0.956 & 0.965 & 0.974 & 0.976 & 1 \\
\hline $\begin{array}{l}\text { Loss of } \\
\text { VSC3 }\end{array}$ & 0.986 & 0.962 & 0.975 & 0.983 & 0.979 & 0.974 & 1 \\
\hline $\begin{array}{l}\text { Loss of } \\
\text { VSC4 }\end{array}$ & 1.01 & 0.992 & 1.007 & 1.01 & 0.996 & 0.983 & 1 \\
\hline $\begin{array}{l}\text { Loss of } \\
\text { VSC5 }\end{array}$ & 0.976 & 1.001 & 1.003 & 1.002 & 0.987 & 0.976 & 1 \\
\hline $\begin{array}{l}\text { Loss of } \\
\text { VSC6 }\end{array}$ & 0.973 & 0.9751 & 0.965 & 0.979 & 0.973 & 0.984 & 1 \\
\hline $\begin{array}{l}\text { Adjusted Converter Power(p.u) } \\
\mathbf{P}_{\text {ref1 }}=0.0836, \mathbf{P}_{\text {ref2 } 2}=0.0905, \mathbf{P}_{\text {ref3 } 3}=0.1567, \mathbf{P}_{\text {ref4 }}=-0.2, \mathbf{P}_{\text {ref5 }}==-0.15, \mathbf{P}_{\text {ref6 } 6=-} \\
0.11, \mathbf{P}_{7}=0.1292\end{array}$ \\
\hline
\end{tabular}

Tables III to XI present the results with the adjusted converter power settings, obtained by the proposed conventional and 
intelligent optimization techniques, as described in section-IV, for the three different objective functions. The voltages are within desired limits in the pre-fault and all the post-fault cases. From tables, it can be observed that the Alternative-1 formulation gives the most optimal results as the DC voltages of the VSCs for both the pre- and post- fault cases are closer to their nominal value 1 p.u.

TABLE VII

DC VOLTAGES SUBJECT TO GA BASED VSC POWER SETTING ADJUSTMENT WITH EXISTING FORMULATION [5]

\begin{tabular}{|l|c|c|c|c|c|l|c|}
\hline \multirow{2}{*}{ Conditions } & \multicolumn{7}{|c|}{ DC Voltage (p.u.) } \\
\cline { 2 - 8 } & $\mathbf{V}_{\mathrm{dc} 1}$ & $\mathbf{V}_{\mathrm{dc} 2}$ & $\mathbf{V}_{\mathrm{dc} 3}$ & $\mathbf{V}_{\mathrm{dc} 4}$ & $\mathbf{V}_{\mathrm{dc} 5}$ & $\mathbf{V}_{\mathrm{dc} 6}$ & $\mathbf{V}_{\mathrm{dc} 7}$ \\
\hline $\begin{array}{l}\text { All VSCs } \\
\text { in service }\end{array}$ & 0.978 & 0.963 & 0.955 & 0.998 & 0.953 & 0.957 & 1 \\
\hline $\begin{array}{l}\text { Loss of } \\
\text { VSC1 }\end{array}$ & 0.957 & 0.958 & 0.964 & 0.987 & 0.986 & 0.986 & 1 \\
\hline $\begin{array}{l}\text { Loss of } \\
\text { VSC2 }\end{array}$ & 0.961 & 0.963 & 0.963 & 0.958 & 0.974 & 0.985 & 1 \\
\hline $\begin{array}{l}\text { Loss of } \\
\text { VSC3 }\end{array}$ & 0.956 & 0.965 & 0.982 & 0.983 & 1.031 & 1.019 & 1 \\
\hline $\begin{array}{l}\text { Loss of } \\
\text { VSC4 }\end{array}$ & 0.987 & 0.951 & 0.973 & 0.976 & 0.986 & 0.976 & 1 \\
\hline $\begin{array}{l}\text { Loss of } \\
\text { VSC5 }\end{array}$ & 0.967 & 1.002 & 0.965 & 0.974 & 0.985 & 0.999 & 1 \\
\hline $\begin{array}{l}\text { Loss of } \\
\text { VSC6 }\end{array}$ & 1.022 & 1.037 & 1.034 & 1.038 & 1.03 & 1.027 & 1 \\
\hline
\end{tabular}

Adjusted Converter Power(p.u)

$\mathbf{P}_{\text {refl }}=0.0036, \mathbf{P}_{\text {ref2 }}=0.009, \mathbf{P}_{\text {ref3 }}=0.2378, \mathbf{P}_{\text {ref } 4}=-0.2, \mathbf{P}_{\text {ref5 }}=-0.15, \mathbf{P}_{\text {ref6 }}=-0.11$, $\mathbf{P}_{7}=0.2096$

TABLE VIII

DC VOLTAGES SUBJECT TO GA BASED VSC POWER SETTING ADJUSTMENT FOR ALTERNATIVE-2 FORMULATION

\begin{tabular}{|l|l|l|l|l|l|l|r|}
\hline \multirow{2}{*}{ Conditions } & \multicolumn{7}{|c|}{ DC Voltage (p.u.) } \\
\cline { 2 - 8 } & $\mathbf{V}_{\mathrm{dc} 1}$ & $\mathbf{V}_{\mathrm{dc} 2}$ & $\mathbf{V}_{\mathrm{dc} 3}$ & $\mathbf{V}_{\mathrm{dc} 4}$ & $\mathbf{V}_{\mathrm{dc} 5}$ & $\mathbf{V}_{\mathrm{dc} 6}$ & $\mathbf{V}_{\mathrm{dc} 7}$ \\
\hline $\begin{array}{l}\text { All VSCs } \\
\text { in service }\end{array}$ & 0.967 & 0.97 & 0.9799 & 0.953 & 0.9790 & 0.9546 & 1 \\
\hline $\begin{array}{l}\text { Loss of } \\
\text { VSC1 }\end{array}$ & 0.986 & 0.999 & 0.964 & 0.972 & 0.972 & 0.964 & 1 \\
\hline $\begin{array}{l}\text { Loss of } \\
\text { VSC2 }\end{array}$ & 0.982 & 0.951 & 0.984 & 0.960 & 0.978 & 0.963 & 1 \\
\hline $\begin{array}{l}\text { Loss of } \\
\text { VSC3 }\end{array}$ & 0.973 & 0.971 & 0.959 & 0.981 & 0.957 & 0.957 & 1 \\
\hline $\begin{array}{l}\text { Loss of } \\
\text { VSC4 }\end{array}$ & 0.971 & 0.959 & 0.964 & 0.963 & 1.015 & 1.018 & 1 \\
\hline $\begin{array}{l}\text { Loss of } \\
\text { VSC5 }\end{array}$ & 0.956 & 0.961 & 0.978 & 0.953 & 0.998 & 1.027 & 1 \\
\hline $\begin{array}{l}\text { Loss of } \\
\text { VSC6 }\end{array}$ & 0.961 & 0.979 & 0.983 & 0.953 & 0.963 & 0.974 & 1 \\
\hline \multicolumn{2}{|c|}{} & & & & & & \\
\hline
\end{tabular}

Adjusted Converter Power(p.u)

$\mathbf{P}_{\text {ref1 } 1}=0.008, \mathbf{P}_{\text {ref } 2}=0.0056, \mathbf{P}_{\text {ref3 }}=0.1893, \mathbf{P}_{\text {ref4 }}=-0.2, \mathbf{P}_{\text {ref5 }}=-0.15, \mathbf{P}_{\text {ref6 }}=-0.11$, $\mathbf{P}_{7}=0.2571$

To demonstrate the performance of the evolutionary techniques, the optimization results with the three different objective functions, obtained by GA and $\mathrm{BBO}$, are compared with the results obtained with a conventional method. The results are summarized in Table XII. Table XII shows that for the tested system and parameters chosen the GA provides the lowest final objective function values for all the three formulations. The $\mathrm{BBO}$ technique performed better than the conventional methods. BBO has performed better than GA and other evolutionary algorithms in some applications [17].
TABLE IX

DC VOLTAGES SUBJECT TO BBO BASED VSC POWER SETTING ADJUSTMENT WITH ALTERNATIVE-1 FORMULATION

\begin{tabular}{|c|c|c|c|c|c|c|c|}
\hline \multirow[t]{2}{*}{ Conditions } & \multicolumn{7}{|c|}{ DC Voltage (p.u.) } \\
\hline & $\mathbf{V}_{\mathrm{dc1}}$ & $\mathbf{V}_{\mathrm{dc} 2}$ & $\mathbf{V}_{\mathrm{dc} 3}$ & $\mathbf{V}_{\mathrm{dc} 4}$ & $\mathbf{V}_{\mathrm{dc} 5}$ & $\mathbf{V}_{\mathrm{dc} 6}$ & $\mathbf{V}_{\mathrm{dc} 7}$ \\
\hline $\begin{array}{l}\text { All VSCs } \\
\text { in service }\end{array}$ & 0.987 & 0.978 & 0.959 & 0.975 & 0.971 & 0.979 & 1 \\
\hline $\begin{array}{l}\text { Loss of } \\
\text { VSC1 }\end{array}$ & 0.967 & 0.978 & 0.998 & 0.981 & 0.987 & 0.965 & 1 \\
\hline $\begin{array}{l}\text { Loss of } \\
\text { VSC2 }\end{array}$ & 1.019 & 0.991 & 0.982 & 0.976 & 0.963 & 0.957 & 1 \\
\hline $\begin{array}{l}\text { Loss of } \\
\text { VSC3 }\end{array}$ & 0.993 & 0.99 & 0.99 & 1.004 & 0.982 & 0.983 & 1 \\
\hline $\begin{array}{l}\text { Loss of } \\
\text { VSC4 }\end{array}$ & 0.987 & 0.975 & 0.98 & 0.979 & 0.978 & 0.998 & 1 \\
\hline $\begin{array}{ll}\text { Loss } & \text { of } \\
\text { VSC5 } & \end{array}$ & 1.0001 & 0.985 & 0.966 & 0.985 & 0.964 & 0.984 & 1 \\
\hline $\begin{array}{l}\text { Loss } \\
\text { VSC6 }\end{array}$ & 0.998 & 1.02 & 1.003 & 1.009 & 1.008 & 1.007 & 1 \\
\hline $\begin{array}{r}\text { Adjusted C } \\
\mathbf{P}_{\text {refl }}=0.08 \\
\mathbf{P}_{7}=0.049\end{array}$ & Сाया & & & & & & .11, \\
\hline
\end{tabular}

TABLE X

DC VOLTAGES SUBJECT TO BBO BASED VSC POWER SETTING ADJUSTMENT WITH EXISTING FORMULATION [5]

\begin{tabular}{|l|l|l|l|l|l|l|c|}
\hline \multirow{2}{*}{ Conditions } & \multicolumn{7}{|c|}{ DC Voltage (p.u.) } \\
\cline { 2 - 9 } & $\mathbf{V}_{\mathrm{dc} 1}$ & $\mathbf{V}_{\mathrm{dc} 2}$ & $\mathbf{V}_{\mathrm{dc} 3}$ & $\mathbf{V}_{\mathrm{dc} 4}$ & $\mathbf{V}_{\mathrm{dc} 5}$ & $\mathbf{V}_{\mathrm{dc} 6}$ & $\mathbf{V}_{\mathrm{dc} 7}$ \\
\hline $\begin{array}{l}\text { All VSCs } \\
\text { in service }\end{array}$ & 0.982 & 0.958 & 0.978 & 0.963 & 0.957 & 0.974 & 1 \\
\hline $\begin{array}{l}\text { Loss of } \\
\text { VSC1 }\end{array}$ & 0.979 & 0.953 & 0.957 & 0.957 & 0.965 & 0.963 & 1 \\
\hline $\begin{array}{l}\text { Loss of } \\
\text { VSC2 }\end{array}$ & 0.991 & 0.987 & 0.997 & 0.951 & 0.976 & 0.976 & 1 \\
\hline $\begin{array}{l}\text { Loss of } \\
\text { VSC3 }\end{array}$ & 0.986 & 0.97 & 0.995 & 0.967 & 0.981 & 0.957 & 1 \\
\hline $\begin{array}{l}\text { Loss of } \\
\text { VSC4 }\end{array}$ & 0.982 & 0.958 & 0.978 & 0.963 & 0.957 & 0.974 & 1 \\
\hline $\begin{array}{l}\text { Loss of } \\
\text { VSC5 } 5\end{array}$ & 0.979 & 0.953 & 0.957 & 0.957 & 0.965 & 0.964 & 1 \\
\hline $\begin{array}{l}\text { Loss of } \\
\text { VSC6 }\end{array}$ & 0.982 & 0.958 & 0.978 & 0.963 & 0.981 & 0.973 & 1 \\
\hline $\begin{array}{l}\text { Adjusted Converter Power(p.u) } \\
\mathbf{P}_{\text {ref1 }=0.00387, ~} \mathbf{P}_{\text {ref2 }}=0.0056, \mathbf{P}_{\text {ref3 }}=0.1467, \mathbf{P}_{\text {ref4 }}=-0.2, \mathbf{P}_{\text {ref5 }}=-0.15, \mathbf{P}_{\text {ref6 }}=- \\
0.11, \mathbf{P}_{7}=0.304\end{array}$ \\
\hline
\end{tabular}

TABLE XI

DC VOLTAGES SUBJECT TO BBO BASED VSC POWER SETTING ADJUSTMENT FOR ALTERNATIVE-2 FORMULATION

\begin{tabular}{|l|l|l|l|l|l|l|r|}
\hline \multirow{2}{*}{ Conditions } & \multicolumn{7}{|c|}{ DC Voltage (p.u.) } \\
\cline { 2 - 9 } & $\mathbf{V}_{\mathrm{dc} 1}$ & $\mathbf{V}_{\mathrm{dc} 2}$ & $\mathbf{V}_{\mathrm{dc} 3}$ & $\mathbf{V}_{\mathrm{dc} 4}$ & $\mathbf{V}_{\mathrm{dc} 5}$ & $\mathbf{V}_{\mathrm{dc} 6}$ & $\mathbf{V}_{\mathrm{dc} 7}$ \\
\hline $\begin{array}{l}\text { All VSCs } \\
\text { in service }\end{array}$ & 0.982 & 0.951 & 0.984 & 0.960 & 0.9782 & 0.963 & 1 \\
\hline $\begin{array}{l}\text { Loss of } \\
\text { VSC1 }\end{array}$ & 0.987 & 0.978 & 0.959 & 0.975 & 0.971 & 0.979 & 1 \\
\hline $\begin{array}{l}\text { Loss of } \\
\text { VSC2 }\end{array}$ & 0.967 & 0.978 & 0.998 & 0.981 & 0.987 & 0.965 & 1 \\
\hline $\begin{array}{l}\text { Loss of } \\
\text { VSC3 }\end{array}$ & 1.003 & 0.964 & 0.984 & 0.985 & 0.973 & 0.989 & 1 \\
\hline $\begin{array}{l}\text { Loss of } \\
\text { VSC4 }\end{array}$ & 0.997 & 1.008 & 1.007 & 0.996 & 0.971 & 0.964 & 1 \\
\hline $\begin{array}{l}\text { Loss of } \\
\text { VSC5 }\end{array}$ & 0.982 & 0.958 & 0.978 & 0.963 & 0.981 & 0.973 & 1 \\
\hline $\begin{array}{l}\text { Loss of } \\
\text { VSC6 }\end{array}$ & 0.978 & 0.986 & 0.976 & 0.963 & 0.974 & 0.954 & 1 \\
\hline $\begin{array}{l}\text { Adjusted Converter Power(p.u) } \\
\mathbf{P}_{\text {ref1 }}=0.0044, \mathbf{P}_{\text {ref2 }}=0.0091, \mathbf{P}_{\text {ref3 }}=0.1782, \mathbf{P}_{\text {ref4 }}=-0.2, \mathbf{P}_{\text {ref5 }}=-0.15, \mathbf{P}_{\text {ref6 }}=- \\
0.11, \mathbf{P}_{7}=0.2683\end{array}$ \\
\hline
\end{tabular}


TABLE XII

COMPARISON OF FINAL OBJECTIVE FUNCTION VALUES WITH DIFFERENT ALGORITHMS

\begin{tabular}{|l|c|c|c|}
\hline $\begin{array}{l}\text { Objective } \\
\text { Function }\end{array}$ & $\begin{array}{l}\text { With } \\
\text { Conventional } \\
\text { (Lagrange } \\
\text { multiplier) } \\
\text { Method (p.u) }\end{array}$ & $\begin{array}{c}\text { With GA } \\
\text { Method } \\
\text { (p.u) }\end{array}$ & $\begin{array}{c}\text { WBO Mith } \\
\text { (p.u) }\end{array}$ \\
\hline $\begin{array}{c}\text { Existing } \\
\text { Optimization } \\
\text { Formulation } \\
\text { [5] }\end{array}$ & 3.3641 & 2.3071 & 2.664 \\
\hline $\begin{array}{c}\text { New } \\
\text { Alternative-1 } \\
\text { Formulation }\end{array}$ & 2.8942 & 2.163 & 2.628 \\
\hline $\begin{array}{c}\text { New } \\
\text { Alternative-2 } \\
\text { Formulation }\end{array}$ & 2.998 & 2.126 & 2.567 \\
\hline
\end{tabular}

As discussed in the literature [17], the $\mathrm{BBO}$ is more sensitive to the immigration and emigration parameters, so additional studies would be necessary to develop the best generic BBO parameters for this test system. By having additional information about the system may enable a better optimization problem formulation and may improve the performance of these algorithms.

\section{SUMMARY}

The two evolutionary computational algorithms have been proposed, in this paper, for the optimal DC voltage and power control in the MVDC shipboard power systems. The MATLAB code has been developed to solve the optimization problem. Test results on a simplified representation of the multi-zonal notional MVDC architecture reveals that the methods proposed, in this work, effectively readjusted and determined the optimal power reference settings of the power dispatchers that maintains the DC voltage at other VSC buses within acceptable limits under the pre-fault as well as the post fault conditions, following the failure of one of the converters.

Three alternative formulations, with different objective functions, were tried out and it is found that the new alternative-1 formulation provides the smallest final objective function. These algorithms have successfully satisfied the specified voltage and power constraints and power balance and had provided the best solution, presented in the paper. To evaluate the performance of the intelligent techniques, the optimization results obtained were compared with the results obtained with a conventional method. The GA provides the best solution for the given optimization problem followed by $\mathrm{BBO}$. The performance of the GA and the $\mathrm{BBO}$ algorithms can be further improved by investigating different ways of generating initial population and by tuning their parameters to achieve even better optimal solution.

\section{ACKNOWLEDGMENTS}

Authors would like to thank the U.S. Office of Naval Research (ONR) for support this research work under Grant N00014-08-1-0080 as part of the Electric Ship Research and
Development Consortium work at Mississippi State University.

\section{REFERENCES}

[1] C. Petry and J. Rumburg, "Zonal electrical distribution systems: An affordable architecture for future," Naval Engineers Journal, vol.105, May 1993, pp. 45-51.

[2] Norbert Doerry, Next Generation Integrated Power System Technology Development Roadmap, November 2007.

[3] RTDS Notional E-ship model Technical guide, Florida State University, Version 3.4, June 2008.

[4] Thomas L. Baldwin and Shani A. Lewis, "Distribution load flow methods for shipboard power systems", IEEE Transactions on Industry Applications, vol. 40, no.5, Sep/Oct 2004, pp. 1183-1190.

[5] Weixing Lu and Boon Teck Ooi, "DC voltage limit compliance in voltage-source converter based multi-terminal HVDC", Proc of IEEE PES General Meeting, 12-16 June 2005, vol. 2, pp. 1322- 1327.

[6] Weixing $\mathrm{Lu}$ and Boon Teck Ooi, "Multiterminal DC transmission system for wind-farms", Proc of IEEE PES Winter Meeting, Columbus, 2001, pp1091-1096.

[7] B. T. Ooi and X. Wang, "Boost type PWM-HVDC transmission system", IEEE Transactions on Power Deliverty, vol. 6, no.4, October 1991, pp. 1557-1563.

[8] Hi Saadat, Power System Analysis, The McGraw-Hill Company, New York, 1999.

[9] N.Mohan, T.M.Undeland and W.P.Robbins, Power ElectronicsConverters, Applications and Design, John Wiley, 1989.

[10] Héctor F. Latorre S, "A Multichoice Control Strategy for a VSCHVDC", PhD dissertation, Royal Institute of Technology, Sweden, 2008.

[11] Xiao-Ping Zhang, " Multi Terminal Voltage- Sourced Converter-Based HVDC models for Power Flow Analysis", IEEE Trans.on Powr Systems, Vol 19, No.4, Nov 2004, pp. 1877-1883.

[12] C. Angeles-Camacho, O.L. Tortelli, E. Acha, and C.R. Fuerte-Esquivel, "Inclusion of a high voltage DC-voltage source converter model in a Newton-Raphson power flow algorithm", IEE Proceedings Generation, Transmission and Distribution -- November 2003, vol 150, Issue 6, p. 691-696

[13] X.F. Yuan, and S. J. Cheng, "Simulation Study for a Hybrid Multiterminal HVDC System", 2005/2006 IEEE Power Engineering Society Transmission and Distribution Conference and Exhibition, , August 2006.

[14] A.M. Cramer,., R.R. Chan, S. D. Sudhoff, Y. Lee, M. R. Surprenant, N. S. Tyler, E. L. Zivi, and R. A. Youngs, "Modeling and simulation of an electric warship integrated engineering plant", presented at SAE Power System Conference, Nov. 2006.

[15] A. Panosyan, and B.R. Oswald, , "Modified Newton-Raphson load flow analysis for integrated AC/DC power systems", Proc. of the 39th International 2004 Universities Power Engineering Conference, 2004., vol 3, on page(s): 1223- 1227.

[16] K. Swain, and A. S. Morris, "A novel hybrid evolutionary programming method for function optimization", Proc. 2000 Congress on Evolutionary Computation, Vol. 1, pp. 699-705, July 2000.

[17] Dan Simon, "Biogeography Based Optimization", IEEE Transactions on Evolutionary Computation, Vol. 12, No. 6, December 2008.

[18] A. Wallace., The Geographical Distribution of Animals (Two Volumes),Adamant Media Corporation, Boston, MA 2005.

[19] A. Darwin., The Origin of Species, New York: Gramercy, 1995.

[20] L. Lai and N. Sinha, " Genetic Algorithms for solving optimal power flow problems", Chapter 17, Modern Heuristic Optimization Techniques", pp. 471-500, IEEE Press, 2008.

[21] E. Goldberg, Genetic Algorithms in Search, optimization and Machine Learning, Addison Wesly, Reading, 1989.

[22] T. Back, Evolutionary Algorithms in Theory and Practice, Oxford, U.K., Oxford University press, 1996.

[23] D. Simon, Optimal State Estimation, Wiley, New York, 2006.

[24] Padmavathy Kankanala, Suresh C Srivastava, Anurag K Srivastava and Noel N Schulz, "Optimal control of Voltage and Power in a Multizonal Shipboard Power System", Proceedings North America Power Symposium (NAPS) 2009 Conference, Starkville, Mississippi, USA

[25] Padmavathy Kankanala, "Optimal Control of Voltage and Power in MVDC Multi-Zonal Shipboard Power System”, Master's thesis, Mississippi State Univeristy, Starkville,USA, 2009. 
[26] Seetharam Raju Rudraraju, "Small Signal and Transient Stability Analysis of MVDC Shipboard Power System', Master's thesis, Mississippi State University, Starkville, USA, 2009.

Padmavathy Kankanala is pursuing her $\mathrm{PhD}$ degree in Electrical Engineering at Kansas State University. She received her Master's degree in Electrical Engineering from Mississippi State University and Bachelor's in Electrical and Electronics Engineering degree from Jawaharlal Nehru Technological University in 2009 and 2006. Her research interest include power system real-time modeling and simulations, application of computational intelligence systems to engineering problems, evolutionary algorithms applications to power engineering, multi-objective optimization.

Suresh C. Srivastava received his $\mathrm{PhD}$ in Electrical Engineering from Indian Institute of Technology, New Delhi, India. He is presently working as Professor in the Department of Electrical Engineering at the Indian Institute of Technology, Kanpur, India. He was also Visiting Faculty at Asian Institute of Technology, Thailand and Mississippi State University, USA during 2008-2009. His research interests include power system optimization, stability and controls, synchrophasor based WAMS, technical issues in electricity markets and MVDC systems. He is a fellow of INAE (India), IE (India) \& IETE (India) and senior member of IEEE.

Anurag K. Srivastava received his Ph.D. from Illinois Institute of Technology (IIT), Chicago, in 2005, his master of technology degree from Institute of Technology, India, in 1999, and his bachelor of technology degree in electrical engineering from Harcourt Butler Technological Institute, India, in 1997. He joined Washington State University as assistant professor in August 2010. He worked as an assistant research professor at Mississippi State University from 2005-2010. Before that, he worked as a research assistant and teaching assistant at IIT, Chicago; as a Senior Research Associate in the Electrical Engineering Department at the Indian Institute of Technology, Kanpur, India; and as a Research Fellow at the Asian Institute of Technology, Bangkok, Thailand. His research interests include smart grid, micro grid, wide-area monitoring and control, real-time simulation, power system modeling, power system security, the electricity market, and artificial intelligence applications in power systems. Dr. Srivastava is member of the IEEE, IET, Power and Energy Society (PES), Sigma Xi, and Eta Kappa Nu. He is vice chair of the IEEE PES career promotion subcommittee and secretary of the IEEE PES student activities subcommittee and is active in several other IEEE PES technical committees.

Noel N. Schulz received her B.S.E.E. and M.S.E.E. degrees from Virginia Polytechnic Institute and State University (Virginia Tech) in 1988 and 1990, respectively. She received her Ph.D. in EE from the University of Minnesota in 1995. She is the Paslay Professor of Electrical and Computer Engineering at Kansas State University. She has served as faculty member at Mississippi State University and Michigan Tech in the past. Her research interests are in computer applications in power system operation including artificial intelligence techniques. She has been active in the IEEE Power and energy Society, serving as President-Elect 2010-11. She is recipient of the IEEE/PES Walter Fee Outstanding Young Power Engineer Award and NSF CAREER award. Dr. Schulz is a member of IEEE, ASEE, SWE, Eta Kappa Nu and Tau Beta Pi. 